\title{
Compound isolated from the cock's comb and its effect on palmar arsenical keratosis
}

\section{Hazera Sharmin and Mir Misbahuddin}

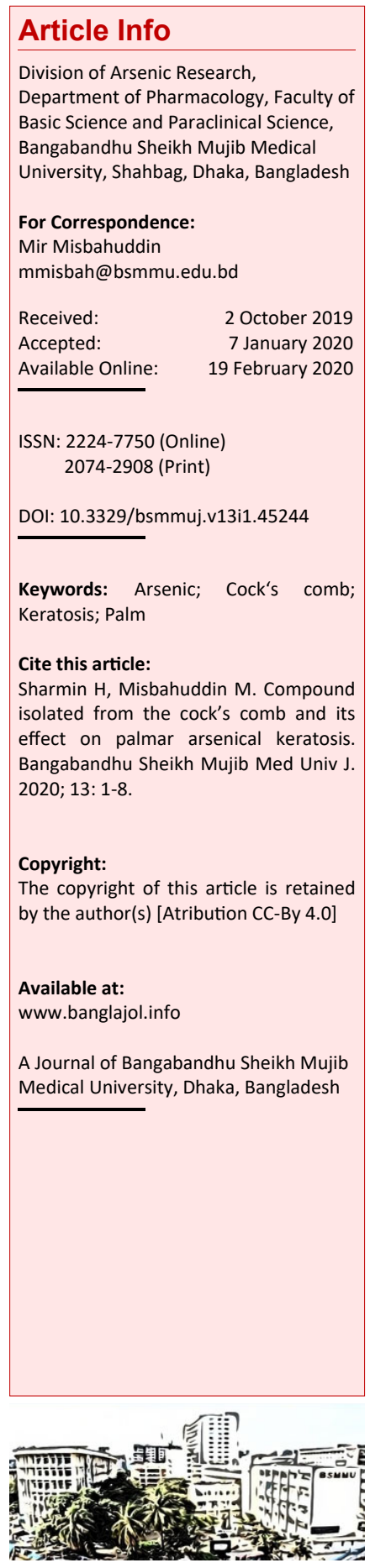

Abstract

This study was conducted to confirm the effectiveness of the ointment containing cock's comb extract and to identify the compound that was effective in the treatment of palmar arsenical keratosis. On the basis of inclusion and exclusion criteria, 24 patients with moderate to severe palmar arsenical keratosis were enrolled from an arsenic endemic area. The ointment prepared from the cock's comb extract was supplied to each patient at an interval of 2 weeks. Each patient was advised to apply the ointment on the nodule by rubbing gently up to 5 minutes and twice daily for 12 weeks. Improvement was monitored by measuring the nodular size before starting and after completion of the treatment. The mean $( \pm$ SD) size of the nodules of the palm before treatment was $16.6 \pm 5.0 \mathrm{~mm}^{2}$, which was reduced to $4.0 \pm 3.8 \mathrm{~mm}^{2}$ after completion of the treatment. This reduction was statistically significant. To identify the effective compound nuclear magnetic resonance spectroscopy, infrared spectrophotometry, elemental analysis and liquid chromatography-mass spectroscopy of the extract were done yet conclusion could not be achieved.

\section{Introduction}

Arsenical keratosis is not only a health problem but also a social hazard in Bangladesh.1 The poor woman is the worst affected patient. The husband of an arsenicosis patient often refuses to keep the marital relationship. The parents of an affected marriageable girl get difficulty to find out a groom. 2 Despite the magnitude of the problem, there is no effective therapy for the treatment of keratosis. .3 Several topical and oral formulations were applied for the treatment of keratosis. However, the beneficial effects of these agents are not established.

A study conducted in this department to see the effectiveness of cock's comb extract in the treatment of palmar arsenical keratosis and was found effective, without any adverse effect. $\underline{4}$ Cock's comb is a big flap of skin. From ancient times, combs were used as food. People in Western Europe and China considered combs as a royal food. 5 Cock's comb consists of hyaluronic acid, chondroitin sulfate, dermatan sulfate and heparan sulfate. The normal desquamation process of the skin is disrupted in keratosis. Desquamation of the skin is maintained by continuous hydration of the stratum corneum. 6 As an occlusive agent hyaluronic acid prevents transepidermal fluid loss.? Chondroitin sulfate also contributes to the hydration of the tissue. 8

So, the purpose of this study was to confirm the beneficial effect of the cock's comb extract and to identify the compound that was effective in the treatment of palmar arsenical keratosis. Extraction of cock's comb on a large scale is difficult, time-consuming and expensive. By identifying the compound, the chemical synthesis will be possible. This may cause the availability of medicine at low cost for the arsenic affected population.

\section{Materials and Methods}

The study was conducted in four places: a) Department of Pharmacology, where extraction and purification of cock's comb, its cytotoxic effects on brine shrimp, ointment preparation, liquid chromatography-mass spectroscopy of the extract and estimation of arsenic in drinking water and nails of the patients were done, b) Patients were enrolled from the Kamalla Union of Muradnagar Upazilla at Cumilla District, c) NMR and IR of the extract were done at the Wazed Miah Science Research Center, Jahangir Nagar University, Savar, Dhaka, d) Elemental analysis of the extract was done at the Bangladesh Council for Scientific and Industrial Research, Dhaka.

\section{Enrollment of patients}

This study was carried out on 24 patients (12 males and 12 females) of palmar arsenical keratosis from September 2017 to January 2019. 
They voluntarily agreed to participate and they were enrolled according to the inclusion and exclusion criteria. Patients aged $>18$ or $<65$ years of both sex with palmar arsenical keratosis, and consumption of arsenic water $(>50 \mu \mathrm{g} / \mathrm{L})$ for more than 6 months were enrolled. An expectant or nursing mother, patient having drug or food allergy especially to avian protein, the patient who received any treatment of arsenicosis within the last 3 months were not enrolled.

\section{Patient's data collection procedure}

The detailed information was taken by interviewing the patients and clinical examinations were done mainly based on arsenical keratosis of the palm of the patients and documented in the case report form.

\section{Measurement of the size of lesion}

The size of the lesion was measured before starting the treatment and 12 weeks after the completion of treatment. Photographs of the lesions were also collected both before and after completion of treatment.

\section{Collection of samples}

To confirm the diagnosis, the water samples as well as the nails were collected before starting the treatment for the estimation of total arsenic level.

\section{Estimation of arsenic}

Estimation of arsenic was done by the modified silver diethyldithiocarbamate method (SDDC). .9

\section{Collection of cock's comb}

The cock's combs $(12 \mathrm{~kg})$ were collected from the poultry shop of a local market and stored in $\left(-20^{\circ} \mathrm{C}\right)$ until extraction.

\section{Method of cock's comb extraction 10}

The combs were squeezed by aqueous separation process. About $500 \mathrm{~g}$ cock's combs were sliced at a time into small pieces. The pieces of combs were soaked in $1 \mathrm{~L}$ of acetone for 24 hours and kept in a refrigerator. After 24 hours, the acetone was squeezed from the materials of the comb and again soaked in $1 \mathrm{~L}$ of acetone for the next 24 hours. This step was repeated four times. After the last extraction, the remaining acetone was dried up in a stream of air. The weight of the dried and defatted combs was about $110 \mathrm{~g}$. These dried combs were submerged in $5 \%$ of $500 \mathrm{~mL}$ solution of sodium acetate for another 24 hours. After 24 hours, the viscous fluid was drawn out by squeezing the sliced combs and then filtered by using normal filter paper. This process was repeated four times. The final comb residue was then disposed of. Ethyl alcohol was added to the aqueous extract. The precipitate formed was pooled, centrifuged, re-dissolved in 5\% sodium acetate solution and re-centrifuged. The protein was removed from the supernatant solution by shaking it with chloroform. Then chloroform-amyl alcohol (1:4 parts) mixture was added several times until a gel no longer formed. The solution was acidified to pH 4.0 and precipitated with ethyl alcohol. After filtration, the precipitate was collected from the filter paper and was weighted about $5.0 \mathrm{~g}$. The solid extract was brown and dissolved in $n$-butanol. According to this procedure, extract was prepared several times. From $12 \mathrm{~kg}$ of cock's comb, $140 \mathrm{~g}$ extract was obtained.

\section{Brine shrimp lethality test $\underline{11}$}

Artificial seawater was prepared into a squareshaped jar by dissolving $27 \mathrm{~g}$ sodium chloride in $3 \mathrm{~L}$ of tap water. About $3 \mathrm{~g}$ of brine shrimp eggs (collected from local market) were poured into the jar for hatching with continuous aeration by airflow machine and artificial light using 60-watt bulb. After 48 hours, the brine shrimp larvae (nauplii) were collected with a Pasteur pipette into five sterile test tubes labeled as I-V.

One milligram of the extract was weighted by an analytical balance. The stock solution was prepared by dissolving the extract in $1 \mathrm{~mL}$ of water. To prepare the different concentrations $(100,10,1.0,0.1$ $\mu \mathrm{g} / \mathrm{mL}$ ), serial dilution of the stock solution was done. About $1 \mathrm{~mL}$ of the prepared solution was taken into each test tube containing actively moving 10 live nauplii in $1 \mathrm{~mL}$ of artificial seawater. The test tubes containing live nauplii were incubated at room temperature. The active movement of nauplii was observed after 2 and 24 hours.

$$
\% \text { Death }=\frac{\text { \#Dead nauplii }}{\text { \#Dead nauplii }+ \text { \#Live nauplii }} \times 100
$$

\section{Preparation of ointment 12}

All the ingredients required to prepare ointment were measured by an analytical balance. A medium -size bowl containing $100 \mathrm{~mL}$ of water was heated up to boiling by a Bunsen burner. A large beaker containing white petroleum (86 g), stearyl alcohol $(3.9 \mathrm{~g})$ and bee wax $(0.08 \mathrm{~g})$ was placed into the bowl. After the complete melting of all the ingredients, the burner was put off. The beaker was cool down at room temperature. The cock's comb extract $(0.1 \mathrm{~g})$ was added and continuously beat until it became thick. Finally, it was poured into the high-density polyethylene container ( $25 \mathrm{~g}$ each) and stored in a cool and dry place until supplying the patient.

\section{Distribution of ointment and periodic monitoring}

Every 2 weeks interval, the ointment was distributed to each patient. The instruction was given how to apply the ointment twice daily over the keratotic lesion of the palm by gently rubbing up to 
Table I

\begin{tabular}{|c|c|c|}
\hline $\begin{array}{c}\text { Concentration of extract } \\
\qquad(\mu \mathrm{g} / \mathrm{mL})\end{array}$ & $\%$ Dead nauplii & $\%$ Net dead nauplii* \\
\hline 0 & $54 \pm 05$ & \\
\hline 1 & $90 \pm 14$ & 36 \\
\hline 10 & $86 \pm 16$ & 32 \\
\hline 100 & $84 \pm 20$ & 30 \\
\hline 1000 & $92 \pm 13$ & 38 \\
\hline
\end{tabular}

$5 \mathrm{~min}$. A printed compliance sheet was given to give a tick mark after applying the ointment. The adherence of the patient and any change in lesion size were monitored by the researcher.

\section{Steps of identification}

The compound was identified by thin layer chromatography, column chromatography, nuclear magnetic resonance spectroscopy, fourier transform infrared spectrophotometry, elemental analysis and liquid chromatography-mass spectroscopy. The light brown peak observed in the thin layer chromatography in a solvent system of chloroform : $n$-hexane (3:3). The light brown com -pound was obtained from column chromatography. This separated compound was dried up with the help of argon gas and collected in Eppendorf tube for NMR, FTIR, elemental analysis and LC-MS. The NMR and FTIR spectra of the cock's comb extract were compared with the reference standard.

\section{Statistical analysis}

Paired ' $\mathrm{t}$ ' test was done to compare the lesion size before and after 12 weeks of treatment and data were presented as mean $\pm \mathrm{SD}$.

\section{Results}

The extract was brown in color, solid in consistency, pungent in smell and soluble in $n$-butanol, but insoluble in methanol, ethanol, chloroform and water. The net dead nauplii were $36 \%$ at $1 \mu \mathrm{g} / \mathrm{mL}$ concentration (Table I).

The mean concentration of arsenic in the fingernail of the patients was $7.5 \mu \mathrm{g} / \mathrm{g}$. The mean concentration of arsenic in the tube well water of the patients was $146 \mu \mathrm{g} / \mathrm{L}$.

\section{Clinical improvement}

The mean size of the keratotic nodules before treatment was $16.6 \mathrm{~mm}^{2}$ which reduced to $4 \mathrm{~mm}^{2}$ after 12 weeks of the study (Table II). The $p$ value
Table II

Size of keratosis before and after applying ointment

\begin{tabular}{|lcc|}
\hline Patient & ment & \\
& & After $\left(\mathrm{mm}^{2}\right)$ \\
\hline 1 & 25.8 & 5.9 \\
2 & 20.2 & 2.0 \\
3 & 22.7 & 1.3 \\
4 & 10.1 & 3.6 \\
5 & 16.6 & 16.6 \\
6 & 10.5 & 0.0 \\
7 & 19.7 & 2.7 \\
8 & 17.6 & 11.1 \\
9 & 12.0 & 4.0 \\
10 & 12.5 & 6.0 \\
11 & 15.0 & 0.0 \\
12 & 16.2 & 1.0 \\
13 & 16.2 & 0.0 \\
14 & 19.9 & 5.5 \\
15 & 19.5 & 0.0 \\
16 & 11.2 & 1.0 \\
17 & 10.1 & 3.8 \\
18 & 17.7 & 4.0 \\
19 & 15.6 & 4.2 \\
20 & 10.5 & 1.0 \\
21 & 14.5 & 4.0 \\
22 & 25.6 & 6.0 \\
23 & 25.6 & 6.0 \\
24 & 14.5 & 5.1 \\
Mean & $16.6 \pm 5.0$ & $4.0 \pm 3.8$ \\
\hline & & \\
\hline
\end{tabular}

was $<0.00001$. The net reduction was about $75 \%$.

\section{Characteristics of the extract}

The compound yield was $1.2 \%$. The retention factor was 0.26 . The mass was 412 . The elemental analysis showed $51 \%$ carbon and $8 \%$ hydrogen. The spectra of FTIR and NMR were compared with the reference standard.

Comparison of wavelength of FTIR spectra with standard reference

Only two waves number were found similar to the standard references those are 1618 and 2924 both for functional group amine (Table III).

Comparison of chemical shifts of ${ }^{13} \mathrm{C}-\mathrm{NMR}$ with standard reference

The chemical shifts were found similar only at the 179, 103 and 23 ppm (Table IV).

Comparison of chemical shifts of ${ }^{1} \mathrm{H}-\mathrm{NMR}$ with standard reference

The chemical shift was found similar at $2 \mathrm{ppm}$ (Table IV). 


\section{Table III}

Comparison of infrared spectra of the extract with standard references

\begin{tabular}{|c|c|c|}
\hline \multicolumn{3}{|c|}{ Wavelength $\left(\mathrm{cm}^{-1}\right)$} \\
\hline Present study & Hafsa et al., 2016 & Reddy and Karunakaran, 2013 \\
\hline 1099 & 1082 & 1041 \\
1165 & 1150 & \\
1379 & 1324 & 1413 \\
1419 & 1409 & 1619 \\
1618 & 1617 & 2896 \\
2854 & 1650 & \\
2924 & 2925 & 3424 \\
3003 & & \\
3415 & 3390 & \\
3469 & & \\
3547 & & \\
\hline
\end{tabular}

\section{Discussion}

Topical application of the cock's comb extract on patients with moderate to severe palmar arsenical keratosis was found effective by measuring the nodular size before and after the completion of the treatment. This is the second study to evaluate the effects of the cock's comb extract on arsenical keratosis. In the previous study,, 4 there was $84 \%$ reduction of the nodular size. In the present study, $75 \%$ reduction of the size of the nodule was observed. The study was statistically significant.
However, $100 \%$ improvement was not observed in this study. Perhaps by increasing the duration of treatment or frequency of administration, 100\% improvement might have been achieved.

There were several studies conducted to assess the effectiveness of different treatment options applied in patients with palmar arsenical keratosis. In 2007, a study showed there was a significant decrease in blood arsenic level after the supplementation of folic acid. $\underline{13}$ Arsenic is methylated to monomethylarsenic and dimethylarsenic acids on folatedependent metabolism, as a result, increases urinary arsenic excretion. But folic acid may cause nausea, vomiting, skin rashes and depression.

A trial was conducted to show the effectiveness of oral administration of a low dose of acitretin in combination with salicylic acid. $\underline{14}$ In that trial, severe mucocutaneous adverse effect was reported with acitretin.

Another study showed the effectiveness of the oral administration of garlic oil for the treatment of mild to moderate degree of palmar arsenical keratosis. $\underline{15}$ In which, garlic oil was administered in the form soft capsule $(10 \mathrm{mg})$ daily for 12 weeks. The study found that there was a reduction of the total accumulated arsenic from the body with the improvement of the nodular size. But, treatment with garlic caused several adverse effects such as gastric irritation, vertigo, diarrhea, and constipation. Besides, the smell was a common discomfort in the treatment with garlic.

In 2014, a study was conducted to show the effect of

\section{Table IV}

\section{Comparison of chemical shifts ( $\delta$ in ppm) of ${ }^{13} \mathrm{C}$ NMR spectra of the extract with standard references}

\begin{tabular}{|c|c|c|c|c|c|c|}
\hline \multicolumn{3}{|c|}{ Present study } & \multicolumn{2}{|c|}{ Rosa et al., 2012} & \multicolumn{2}{|c|}{ Bociek et al., 1980} \\
\hline N-acetyl & glucosamine & Glucuronic acid & $\begin{array}{c}\mathrm{N}-\text { acetyl } \\
\text { glucosamine }\end{array}$ & Glucuronic acid & $\begin{array}{c}\mathrm{N} \text { - acetyl } \\
\text { glucosamine }\end{array}$ & Glucuronic acid \\
\hline & & 179 & & 176 & & 177 \\
\hline & 103 & 105 & 103 & 106 & 103 & 104 \\
\hline & & & 71 & & 71 & \\
\hline & 65 & & 63 & & 62 & \\
\hline & 50 & & 57 & & 56 & \\
\hline & 23 & & 25 & & 23 & \\
\hline \multicolumn{7}{|c|}{${ }^{1} \mathrm{H}$ NMR spectra } \\
\hline \multicolumn{3}{|c|}{ Present study } & Welti et al., 1978 & & \multicolumn{2}{|l|}{ Wende et al., 2016} \\
\hline & 4.46 & 4.29 & 4.5 & 4.4 & 5.1 & 5.1 \\
\hline \multirow{4}{*}{\multicolumn{2}{|c|}{3.65}} & 3.43 & 3.8 & 3.3 & 4.0 & 3.8 \\
\hline & & & & 3.5 & 4.0 & 4.0 \\
\hline & & & & 3.7 & 3.5 & 5.9 \\
\hline & & & 3.4 & & 3.9 & \\
\hline & 2.0 & & 2.0 & & 2.1 & \\
\hline
\end{tabular}


Nigella sativa on palmar arsenical keratosis. .16 The disadvantage of that study was maximum patients suffered from gastric irritation during the study period.

Another study evaluated the effectiveness of the topical administration of salicylic acid for the treatment of palmar arsenical keratosis. 17 An ointment containing $20 \%$ and $30 \%$ of salicylic acid had been found more effective. There were burning sensation and pruritus due to long-term administration of a high concentration of salicylic acid.

A trial was conducted to evaluate the effectiveness of the topical administration of propylene glycol in the treatment of palmar arsenical keratosis. 18 The disadvantage of that study was itching of the patients.

A study was conducted to evaluate the effect of the extract of leaves of Azadirachta indica on the palmar arsenical keratosis. 19 The common problems of that study were foul-smelling and burning sensation.

In the present study, the effectiveness of the topical administration of cock's comb extract was further evaluated. Cock's comb composed of hyaluronic acid, chondroitin sulfate, dermatan sulfate and heparan sulfate. $20-22$

The topical administration of ointment containing cock's comb extract maintains the hydrophilic state in the stratum corneum. By retaining a large amount of water it keeps the skin much more hydrated and repeated hydration regulates the desquamation process. The intracellular lipids also regulate the normal desquamation process, which is also maintained by the hydration of the stratum corneum. $\underline{23}$ In case of keratosis, excess deposition of the keratin occurs and the natural desquamation process is hampered. It can be considered that the administration of ointment containing cock's comb extract reduces the size of the keratosis by desquamation process and can be used effectively in the treatment of palmar arsenical keratosis.

Chondroitin sulfate is another component of the cock's comb. It also contributes to the hydration of the tissue; inhibits the release of free reactive oxygen species, nitric oxide. $\frac{8}{}$

Dermatan sulfate plays a critical role in the development of the central nervous system, wound repair, infection control, morphogenesis and cell division. 24

Heparan sulfate can attach extracellular superoxide dismutase to the endothelial cell surface and thus play a role as an antioxidant. It also activates antithrombin III which inhibits the coagulation process at several steps. .25

This study showed that the ointment containing cock's comb extract was found effective in the treatment of moderate to severe arsenical keratosis, without any systemic adverse effects. To identify the effective compound, nuclear magnetic resonance spectroscopy, fourier-transform infrared spectrophotometry, elemental analysis and liquid chromatography-mass spectrometry of the extract were done.

Several studies were conducted to identify hyaluronic acid extracted from different sources. In 2003, a study was conducted to purify hyaluronic acid from the mollusc bivalve Mytilus galloprovincialis, using ${ }^{13} \mathrm{C}$ nuclear magnetic resonance spectroscopy. .6 In that study, the spectra for glucuronic acid units were observed at $106.0 \mathrm{ppm}$ for $\mathrm{C}-1,75.3 \mathrm{ppm}$ for C-2, $76.3 \mathrm{ppm}$ for $\mathrm{C}-3,82.7 \mathrm{ppm}$ for $\mathrm{C}-4,79.0$ ppm for $\mathrm{C}-5$, and $177.0 \mathrm{ppm}$ for $\mathrm{C}=\mathrm{O}$. The spectra observed for n- acetylglucosamine units were at 103.5 ppm, 57.1 ppm, 85.3 ppm, 71.2 ppm, 78.5 ppm, 68.3 ppm for C-1, C-2, C-3, C-4, C-5, and C-6 respectively.

Another study was conducted with the human umbilical cord, 27 and identified carboxyl and acetamide groups at 173.4 and 144.5 ppm, respectively, two anomeric carbons at 100.1 and $102.7 \mathrm{ppm}$ and an acetamide carbon at $22.1 \mathrm{ppm}$. The signals observed at 53.9 and $60.4 \mathrm{ppm}$ for the C2 and C6 carbons of the glucosamine residue.

In 2012, another study was conducted to identify hyaluronic acid extracted from the cock's comb. $\underline{28}$ The ${ }^{13} \mathrm{C}$ nuclear magnetic resonance spectra of that study found that for glucuronic acid units the chemical shifts were observed at $177.0 \mathrm{ppm}$ for COO- , at $106.0 \mathrm{ppm}$ for C-1, at $83.0 \mathrm{ppm}$ for C-4, at $79.4 \mathrm{ppm}$ for C-5, at $76.7 \mathrm{ppm}$ for C-3 and C-2 at $75.6 \mathrm{ppm}$. For the $n$-acetylglucosamine units, a signal was observed at $178.0 \mathrm{ppm}$ for the C-2 carbons, and signals identified at 103.4, 85.5, 78.4, 71.6, 63.5 and 57.3 ppm corresponding to the C-1, C$3, \mathrm{C}-5, \mathrm{C}-4, \mathrm{C}-6$ and C-2 carbons, respectively. At 25.5 ppm, a characteristic shift for the methylic carbon was observed. In the ${ }^{13} \mathrm{C}$ nuclear magnetic resonance spectra of this study signals observed for glucuronic acid units were at $105.8 \mathrm{ppm}$ for C-1, and signal observed at 179.3 for $\mathrm{C}=\mathrm{O}$. The chemical shifts observed for $n$-acetylglucosamine units were at $103.2 \mathrm{ppm}, 50.8 \mathrm{ppm}$, and $65.5 \mathrm{ppm}$, corresponding to C-1, C-2, C-3. A characteristic methylic carbon was observed at $23.0 \mathrm{ppm}$.

${ }^{1} \mathrm{H}$-magnetic resonance is another useful tool for the identification of hyaluronic acid. In 1979, a study was conducted to compare the conformational changes of spectra of hyaluronic acid chondroitin sulfate that occur in alkaline solution.29 In that study, spectra observed in neutral solution were as follows: at $4.4 \mathrm{ppm}, 3.3 \mathrm{ppm}, 3.5 \mathrm{ppm}$ and $3.7 \mathrm{ppm}$ for $\mathrm{H}-1, \mathrm{H}-2, \mathrm{H}-3$, and $\mathrm{H}-4$ respectively for the glucuronic acid units. Spectra observed for nacetylglucosamine units were as follows: at 4.5 ppm, $3.8 \mathrm{ppm}, 3.7 \mathrm{ppm}, 3.5 \mathrm{ppm}, 3.4 \mathrm{ppm}$ and 4.0 ppm for H-1, H-2, H-3, H-4, H-5, H-6 and H-6' respectively. A spectrum observed at $2.0 \mathrm{ppm}$ for 
acetamidomethyl proton.

Another study was conducted to determine hyaluronic acid using NMR and mass spectrometry -based methods. .30 In that study, ${ }^{1} \mathrm{H}$-magnetic resonance spectra for a) glucuronic acid units observed at $5.1 \mathrm{ppm}, 3.8 \mathrm{ppm}, 4.0 \mathrm{ppm}, 6.0 \mathrm{ppm}$ for $\mathrm{H}-1, \mathrm{H}-2, \mathrm{H}-3$, and $\mathrm{H}-4$ respectively and spectra for b) n-acetylglucosamine units observed at $5.1 \mathrm{ppm}$, $4.0 \mathrm{ppm}, 4.0 \mathrm{ppm}, 3.5 \mathrm{ppm}, 4.0 \mathrm{ppm}, 3.8 \mathrm{ppm}$, and 3.8 ppm for H-1, H-2, H-3, H-4, H-5, H-6 and H-6' respectively. A spectrum observed at $2.1 \mathrm{ppm}$ for acetamidomethyl proton.

On the other hand, ${ }^{1} \mathrm{H}$ NMR spectra of this study were as follows: - For glucuronic acid units- at 4.29 ppm and 3.43 ppm for $\mathrm{H}-1$ and $\mathrm{H}-2$ respectively. For n-acetylglucosamine units- at $4.46 \mathrm{ppm}$ and 3.65 ppm for $\mathrm{H}-1, \mathrm{H}-2$ respectively and spectrum observed at $2.0 \mathrm{ppm}$ for acetamidomethyl proton.

Characterization of hyaluronic acid by the fourier transform infrared spectroscopy is another useful method. A study was conducted to evaluate the effect of ultrasonic degradation of hyaluronic acid extracted from rooster comb on antioxidant and antiglycation activities. $\underline{31}$ In that study, the main spectra of the fourier transform infrared spectroscopy indicate an $\mathrm{O}-\mathrm{H}$ and $\mathrm{N}-\mathrm{H}$ stretching vibrations at $3390 \mathrm{~cm}^{-1}, \mathrm{C}-\mathrm{H}$ stretching vibrations at 2925 $\mathrm{cm}^{-1}$. The spectra at 1617 and $1409 \mathrm{~cm}^{-1}$ were due to $\mathrm{N}-\mathrm{H}$ and $\mathrm{C}-\mathrm{O}$ stretching modes of the planar carboxyl groups. The absorption spectra about 1650, 1551 and $1324 \mathrm{~cm}^{-1}$ correspond to the amide I, II and III, respectively, C-O-C group at $1150 \mathrm{~cm}^{-1}(\mathrm{O}-$ bridge) and the $\mathrm{C}-\mathrm{O}-\mathrm{H}$ group at $1041 \mathrm{~cm}^{-1}$.

Another study was conducted where purification and charac-terization of hyaluronic acid were produced by Streptococcus zooepidemicus strain 35237.32 In that study, the significant spectra $\left(\mathrm{cm}^{-1}\right)$ were at 611.3 , at 1043.3 that could be due to the C-O-C stretching, at 1411.6 that corresponds to the presence of $\mathrm{C}-\mathrm{O}$ group with $\mathrm{C}=\mathrm{O}$ combination, at 1616.0 that indicates the presence of amid II group, at 2892.7 due to the $\mathrm{C}-\mathrm{H}$ stretching and at 3407.6 that confirms the presence of $\mathrm{OH}$ stretching.

In the present study, the spectra of fourier transform infrared spectroscopy $\left(\mathrm{cm}^{-1}\right)$ of cock's comb extract are at 3547.0 due to O-H stretching, at 3469.0 due to N-H stretching, at 3003.1 due to $\mathrm{O}-\mathrm{H}$ stretching for carboxylic acid, at 2854.6 due to $\mathrm{O}-\mathrm{H}$ stretching for alcohol, peak at 1618.0 due to $\mathrm{N}-\mathrm{H}$ stretching and at 1165.0 due to C-O stretching for ester.

The nuclear magnetic resonance $\left({ }^{13} \mathrm{C}\right.$ and $\left.{ }^{1} \mathrm{H}\right)$ and the fourier transform infrared spectrophotometry data of this study were not consistent with that of previous studies, conducted to identify hyaluronic acid extracted from a different source and could not support the presence of hyaluronic acid in this extract.
Elemental analysis of the extract was done but the conclusion was not achieved. The report showed that there was $51.4 \%$ carbon and $8.13 \%$ hydrogen. Nitrogen was not detectable in the extract and there was a lack of facility to obtain the percentage of oxygen and sulfur. From the molecular structure of hyaluronic acid, chondroitin sulfate, dermatan sulfate and heparan sulfate, it was revealed that all of them contain nitrogen. Anal. Calcd for $\mathrm{C}_{28} \mathrm{H}_{44} \mathrm{~N}_{2} \mathrm{O}_{23}$ (hyaluronic acid): $\mathrm{C}, 43.41 ; \mathrm{H}, 5.42 ; \mathrm{N}$, 3.61; O, 47.54; Anal. Calcd for $\mathrm{C}_{14} \mathrm{H}_{21} \mathrm{NO}_{15} \mathrm{~S}$ (dermatan sulfate): $\mathrm{C}, 34.35 ; \mathrm{H}, 4.29 ; \mathrm{N}, 2.94 ; \mathrm{O}$, 49.07; S, 6.54; Anal. Calcd for $\mathrm{C}_{13} \mathrm{H}_{21} \mathrm{NO}_{15} \mathrm{~S}$ (chondroitin sulfate): $\mathrm{C}, 33.69 ; \mathrm{H}, 4.53 ; \mathrm{N}, 3.02 ; \mathrm{O}$, 51.83; S, 6.91; Anal. Calcd for $\mathrm{C}_{14} \mathrm{H}_{23} \mathrm{NO}_{21} \mathrm{~S}_{3}$ (heparan sulfate): C, 26.37; H, 3.61; N, 2.19; O, 52.74; S, 15.07.

In the liquid chromatography-mass spectroscopy method, the mass of the extract was found 412.8 Dalton. The molecular mass of hyaluronic acid, heparan sulfate, dermatan sulfate and chondroitin sulfate are about 776 Dalton, 637 Dalton, 475.37 Dalton and 463.36 Dalton respectively.

\section{Conclusion}

The present study confirms the effectiveness of the cock's comb extract in the treatment of palmar arsenical keratosis. By analyzing the NMR, FTIR, elemental analysis and LC-MS, it can be said that the effective compound was something else other than hyaluronic acid, heparan sulfate, dermatan sulfate and chondroitin sulfate.

\section{Ethical Issue \\ The protocol was approved by the Institutional Review Board of Bangabandhu Sheikh Mujib Medical University (Reg. No. BSMMU/2018/2966). This study was registered on the clinical trial.gov. the registration No. was NCT03635853. The participants were informed about the risks, benefits and possible outcomes of this work and the information were given in an easy and local language (Bengali). Informed written consent was taken from each patient.}

\section{Acknowledgements}

We are grateful to Mrs. Shamima Akter, Health Assistant of Kamalla Union and villagers of Kamalla for their co-operation during the study period.

\section{References}

1. Misbahuddin M, Khandker S, Jakariya M. Arsenic contamination of drinking water and foodstuffs. In: Drinking water contaminants in Bangladesh: Focuses on arsenic, fluoride, pesticides, manganese and cyanobacteria. Misbahuddin M, Khandker S 
(eds). Lambert Academic Publishing, Germany, 2011, pp 12-57.

2. Alam MGM, Allinson G, Stagnitti F, Tanaka A, Westbrooke M. 2002. Arsenic contamination in Bangladesh groundwater: A major environmental and social disaster. Int J Environ Health Res. 2002; 12: $235-53$.

3. Misbahuddin M. Arsenicosis: A global issue. New York, Science Publishing Group, 2015, pp 1204.

4. Anny F, Misbahuddin M. Effect of cock's comb extract in the treatment of palmar arsenical keratosis. Bangladesh J Pharmacol. 2019; 14: 87-92.

5. Kawada C, Yoshida T, Yoshida H, Matsuoka R, Sakamoto W, Odanaka W, Sato T, Yamasaki T, Kanemitsu T, Masuda Y, Urushibata O. Ingested hyaluronan moisturizes dry skin. Nutr J. 2014; 13: 70-78.

6. Rawlings AV, Matts PJ. Stratum corneum moisturization at the molecular level: An update in relation to the dry skin cycle. J Invest Dermatol. 2005; 124: 1099-110.

7. Draelos ZD. A clinical evaluation of the comparable efficacy of hyaluronic acid-based foam and ceramide-containing emulsion cream in the treatment of mild-to-moderate atopic dermatitis. J Cosmetic Dermatol. 2011; 10: 185-88.

8. Lamari FN. The potential of chondroitin sulfate as a therapeutic agent. Connect Tissue Res. 2008; 49: 289-92.

9. Bhuiyan HA, Tshering K, Misbahuddin M. Estimation of arsenic in nail using silver diethyldithiocarbamate method. Bangladesh J Pharmacol. 2015; 10: 513-17.

10. Boas NF. Isolation of hyaluronic acid from the cock's comb. J Biol Chem. 1949; 181: 573-75.

11. Sarah QS, Anny FC, Misbahuddin M. Brine shrimp lethality assay. Bangladesh J Pharmacol. 2017; 12: 186-89.

12. Block LH. Ointments. In: Remington: The science and practice of pharmacy. Genaro AR (ed). 20th ed. Vol. 1. 2000, pp. 845-46.

13. Gamble MV, Liu X, Slavkovich V, Pilsner JR, Ilievski V, Factor-Litvak P, Levy D, Alam S, Islam M, Parvez F, Ahsan H. Folic acid supplementation lowers blood arsenic. Am J Clin Nutr. 2007; 86: 1202-09.

14. Son SB, Song HJ, Son SW. Successful treatment of palmoplantar arsenical keratosis with a combination of keratolytics and low-dose acitretin. Clin Exp Dermatol. 2008; 33: 202-04.

15. Misbahuddin M, Bashar T, Hossain MA. Effectiveness of garlic oil in the treatment of arsenical palmer keratosis. Bangladesh J Pharmacol. 2013; 8: 22-27.
16. Bashar T, Misbahuddin M, Hossain MA. A doubleblind, randomize, placebo-control trial to evaluate the effect of Nigella sativa on palmer arsenical keratosis patients. Bangladesh J Pharmacol. 2014; 9: 15-21.

17. Islam AZMM, Misbahuddin M, Sikdar S, Biswas AK, Islam Z, Hadiuzzaman KS, Mahmud IA, Ahmad SA. Randomized controlled trial to evaluate the effectiveness of topical use of salicylic acid for treatment of keratosis in arsenicosis patients. In: Applied research on arsenic in Bangladesh. Misbahuddin M (ed). World Health Organization (Dhaka, Bangladesh), Directorate General of Health Services, Government of Bangladesh, 2007, pp 92-100.

18. Dina AN, Misbahuddin M. Randomized doubleblind trial to evaluate the effectiveness of topical administration of propylene glycol in arsenical palmer keratosis. Bangladesh J Pharmacol. 2010; 5: 98-102.

19. Ferdoush J, Misbahuddin M. Effect of ethanol extract of leaves of Azadirachta indica on palmar arsenical keratosis: A single-blind trial. Bangladesh J Pharmacol. 2014; 9: 279-83.

20. Sasai Y. Identification of individual acid mucopolysaccharide in tissue sections. Tohoku J Exp Med. 1971; 105: 101-10.

21. Hang KFNK, Anastassiadis PA. Glycosaminoglycans of tissues of the domestic fowl. Can J Biochem. 1980; 58: 319-24.

22. Nakano T, Sim JS. Glycosaminoglycans from the rooster comb and wattle. Poult Sci. 1989; 68: 130306 .

23. Egelrud T. Desquamation in the stratum corneum. Acta Dermato-Venereologica. 2000; 208: 44-45.

24. Sugahara K, Mikami T, Uyama T, Mizuguchi S, Nomura K, Kitagawa H. Recent advances in the structural biology of chondroitin sulfate and dermatan sulfate. Curr Opin Struct Biol. 2003; 13: 61220.

25. Ihrcke NS, Wrenshall LE, Lindman BJ, Platt JL. Role of heparan sulfate in immune system-blood vessel interactions. Immunol Today. 1993; 14: 50005 .

26. Volpi N, Maccari F. Purification and characterization of hyaluronic acid from the mollusc bivalve Mytilus galloprovincialis. Biochimie 2003; 85: 619-25.

27. Lago G, Oruña L, Cremata JA, Pérez C, Coto G, Lauzan E, Kennedy JF. Isolation, purification and characterization of hyaluronan from human umbilical cord residues. Carbohydr Polym. 2005; 62: $321-26$

28. Rosa CSD, Tovar AF, Mourão P, Pereira R, Barreto $\mathrm{P}$, Beirão LH. Purification and characterization of hyaluronic acid from chicken combs. Ciência Rural. 2012; 42: 1682-87. 
29. Welti D, Rees DA, Welsh EJ. Solution conformation of glycosaminoglycans: Assignment of the 300$\mathrm{MHz}{ }^{1} \mathrm{H}$-magnetic resonance spectra of chondroitin 4-sulphate, chondroitin 6-sulphate and hyaluronate, and investigation of an alkali-induced conformation change. Eur J Biochem. 1979; 94: 505-14.

30. Wende FJ, Gohil S, Mojarradi H, Gerfaud T, Nord LI, Karlsson A, Boiteau JG, Kenne AH, Sandström C. Determination of substitution positions in hyaluronic acid hydrogels using NMR and MS based methods. Carbohydr Polym. 2016; 136: 1348-
57

31. Hafsa J, Chaouch MA, Charfeddine B, Rihouey C, Limem K, Le Cerf D, Rouatbi S, Majdoub H. Effect of ultrasonic degradation of hyaluronic acid extracted from rooster comb on antioxidant and antiglycation activities. Pharm Biol. 2017; 55: 156-63.

32. Reddy KJ, Karunakaran KT. Purification and characterization of hyaluronic acid produced by Streptococcus zooepidemicus strain 3523-7. J Biol Sci Biotechnol. 2013; 2: 173-79. 